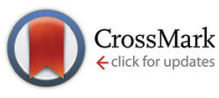

Cite this: Org. Biomol. Chem., 2016, 14, 1930

Received 6th January 2016,

Accepted 14th January 2016

DOI: $10.1039 / c 6 o b 00023 a$

www.rsc.org/obc

\section{Synthesis and evaluation of a desymmetrised synthetic lectin: an approach to carbohydrate receptors with improved versatility $\dagger$}

\author{
Tiddo J. Mooibroek,* Matthew P. Crump and Anthony P. Davis*
}

\begin{abstract}
A new synthetic lectin features apolar surfaces provided by two different aromatic components (biphenyl and pyrenyl). Affinities up to $260 \mathrm{M}^{-1}$ are recorded for carbohydrates in water. The desymmetrised design has potential for variation to give receptors with a broadened range of capabilities.
\end{abstract}

Carbohydrates are versatile biomolecules employed for diverse purposes ranging from energy management and large-scale construction to protein labelling and cell-cell signalling. ${ }^{1}$ Carbohydrate-binding proteins (lectins) are widely used to help investigate these processes. However the natural lectins are not always ideal as research tools, and there is potential for synthetic analogues to play complementary roles. ${ }^{1 a, e}$ Carbohydrate recognition in water is challenging due to the hydromimetic exterior of carbohydrates; ${ }^{1 e, 2}$ even natural lectins tend to bind their substrates quite weakly. ${ }^{3}$ Nonetheless, if the problem can be solved, synthetic carbohydrate receptors ${ }^{4}$ ("synthetic lectins") could be valuable in glycobiological research, and may ultimately be exploited in medicine. ${ }^{4 b, 5}$

In recent years we have reported a series of synthetic lectins based on the "temple" design strategy illustrated in Fig. 1a. ${ }^{2,4 a, 6}$ Amphiphilic cavities have been constructed from two aromatic surfaces held apart by isophthalamide pillars. The aromatic surfaces can help to bind a carbohydrate substrate through hydrophobic and $\mathrm{CH}-\pi$ interactions, while the isophthalamide pillars provide amide groups which can hydrogen bond to polar groups on the substrate. Variations have included tricyclic, bicyclic and monocyclic frameworks (e.g. $3-5),{ }^{6 a_{j} j}$ but all have featured two identical apolar surfaces. This arrangement is complementary to all-equatorial carbohydrates, such as $\beta$-glucosyl (1) and $\beta$ - $N$-acetylglucosaminyl $(\beta$-GlcNAc) (2), which possess two roughly similar hydrophobic

School of Chemistry, University of Bristol, Cantock's Close, BS8 1TS Bristol, UK. E-mail: tiddomooibroek@gmail.com, anthony.davis@bristol.ac.uk

$\dagger$ Electronic supplementary information (ESI) available: Experimental details for syntheses and measurements of binding constants. See DOI: 10.1039/ c6ob00023a faces. Accordingly, the receptors have shown good affinities and excellent selectivities for this family of substrates.

Having succeeded with the all-equatorial saccharides, we would like to expand the scope of these "synthetic lectins" so that a wider range of targets can be addressed. Selectivity for other carbohydrates requires that axial polar substituents should be accommodated. In most cases this will disturb the balance between the faces of the carbohydrate, one becoming more polar while the other gains hydrophobicity. Cavities with matching apolar surfaces are no longer appropriate, but receptors built from two different apolar units (e.g. one large, one small) have potential to succeed. Here we report the first examples of a new generation of desymmetrised carbohydrate receptors with differing roof and floor. This architecture promises greater versatility than the original temple receptors, and could eventually form a family of synthetic lectins with a range of complementary selectivities.

Our approach to designing these new receptors is illustrated in Fig. 1b. A bicyclic structure was chosen to favour a preorganised cavity while avoiding the synthetic challenge of higher connectivity. Preorganisation would be assisted by employing a rigid, condensed aromatic unit as the larger apolar surface. At one end of the cavity two pillars would connect the large and small apolar surfaces, while the third linkage would be variable. This could allow space to accommodate axial substituents in the substrate and otherwise tune selectivity. Our prototype design 7 is shown in Fig. 1c. The rigid floor is provided by the trisubstituted pyrene unit employed in $4 .{ }^{6 j}$ The spacers are isophthalamides with watersolubilising substituents as employed in earlier designs, and the smaller apolar unit is a benzene ring. For this initial work we chose a variable region that would limit flexibility while maintaining ease of synthesis, i.e. a $p$-phenylene linked to a third isophthalamide. The required biphenyl unit was readily accessible, having previously been used in symmetrical receptor $16 .^{6 h}$

Macrobicycle 7 was synthesised as shown in Scheme $1 .^{7}$ Biphenyl $\mathbf{1 0}$ was obtained by Suzuki coupling of $\mathbf{8}^{8}$ and $\mathbf{9},{ }^{6 g}$ followed by a Staudinger reaction with trimethylphosphine. 
(a)

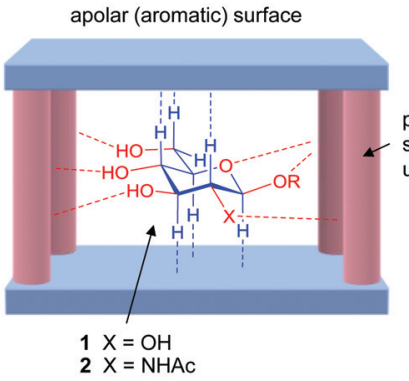

(b)
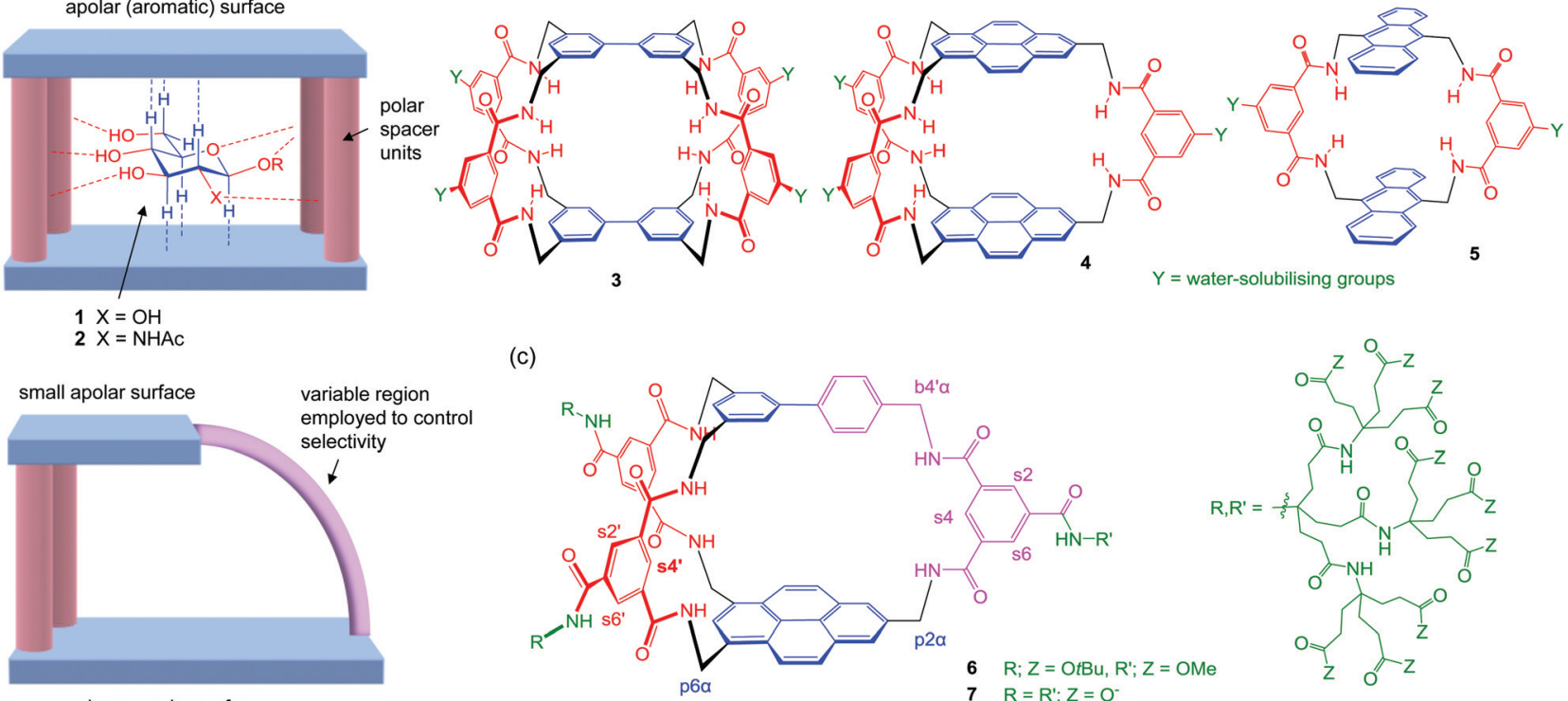

large apolar surface

(c)
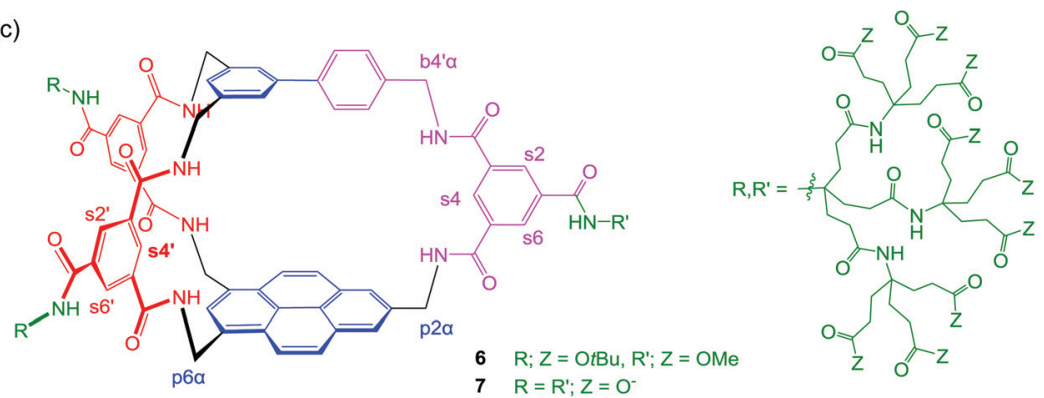

Fig. 1 (a) Design strategy for "temple" receptors targeting all-equatorial carbohydrates. Left: cartoon representation, shown binding $\beta$-glucosyl 1 and $\beta$-GlcNAc 2. Right: reported examples 3-5. (b) Asymmetric architecture with potential for greater versatility. The variable region may be used to accommodate and/or bond to axial carbohydrate substituents. (c) Prototype 7 and protected precursor 6 , showing labels for selected protons ( $p=$ pyrenyl, $\mathrm{b}=$ biphenyl, $\mathrm{s}=$ spacer). The complete labelling system is given in the ESI. $\dagger$
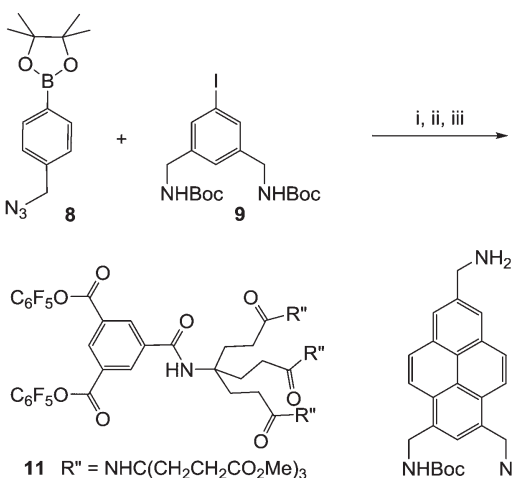

$11 \mathrm{R}^{\prime \prime}=\mathrm{NHC}\left(\mathrm{CH}_{2} \mathrm{CH}_{2} \mathrm{CO}_{2} \mathrm{Me}\right)_{3}$
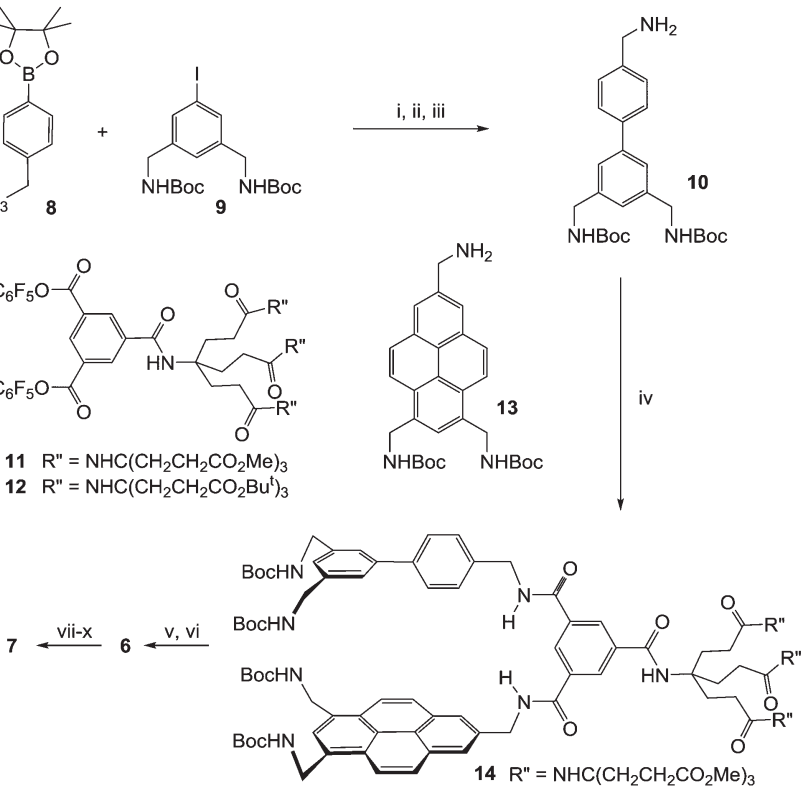

Scheme 1 (i) $\mathrm{K}_{2} \mathrm{CO}_{3}, \mathrm{Pd}\left(\mathrm{PPh}_{3}\right)_{4}, \mathrm{THF} / \mathrm{H}_{2} \mathrm{O}, 12 \mathrm{~h}, 60{ }^{\circ} \mathrm{C}$; (ii) $\mathrm{PMe}_{3}, \mathrm{THF}$, $2 \mathrm{~h}, 60{ }^{\circ} \mathrm{C}$; (iii) $\mathrm{H}_{2} \mathrm{O}, \mathrm{THF}, 12 \mathrm{~h}, 60^{\circ} \mathrm{C}$; $33 \%$ over steps i-iii; (iv) $10+11+$ DIPEA, THF, RT, $30 \mathrm{~min}$, then 13, RT, $30 \mathrm{~min}, 55 \%$; (v) TFA, DCM, $0{ }^{\circ} \mathrm{C}$; $3 \mathrm{~h}$; (vi) DIPEA + 12, THF (high dilution), RT, $120 \mathrm{~h}, 5 \%$ over steps v and vi after HPLC separation from side products; (vii) TFA, DCM, $0 \rightarrow 25{ }^{\circ} \mathrm{C}$, 12 h; (viii) $\mathrm{NaOH}$ aq. (5 M); (ix) amberlyst 15 resin $\mathrm{H}$-form, to $\mathrm{pH}<3$; (x) $\mathrm{H}_{2} \mathrm{O}, \mathrm{NaOH}$ aq. to $\mathrm{pH} 7.1$; $100 \%$ over steps vii-x.

The linear intermediate $\mathbf{1 4}$ was then constructed by treating activated ester $11^{6 j}$ first with $\mathbf{1 0}$ and then with pyrenyl amine 13. ${ }^{6 j}$ Methyl ester protection was employed in $\mathbf{1 1}$ to allow the use of acid-labile NHBoc groups in $\mathbf{1 0}$ and 13. Removal of the Boc groups was followed by macrocyclisation under high dilution with activated ester $12^{6 i}$ to give protected receptor $\mathbf{6}$. As discussed later, macrobicycle $\mathbf{6}$ was accompanied by a side product which necessitated careful separation by HPLC, resulting in a low isolated yield of $5 \%$. However, sufficient material was obtained for characterisation and further studies. Treatment of 6 with TFA, removing $O-t \mathrm{Bu}$ protection, was followed by basic hydrolysis of the methyl ester groups with $\mathrm{NaOH}$. Receptor 7 was isolated from excess salt by acidification with ion exchange resin to give the heptacosa-carboxylic acid. The acid was then dissolved in $\mathrm{D}_{2} \mathrm{O}$ by adjusting the $\mathrm{pH}$ to $\sim 7$ with NaOD. The solutions gave well-resolved ${ }^{1} \mathrm{H}$ NMR spectra which showed some concentration-dependence but were largely unchanged below $0.35 \mathrm{mM}^{7}$ Application of 2D NOESY, COSY and TOCSY methods allowed a full assignment of all aromatic and benzylic proton signals.

The binding properties of 7 towards carbohydrate substrates were investigated using ${ }^{1} \mathrm{H}$ NMR titrations. ${ }^{7}$ Addition of carbohydrates to solutions of 7 in $\mathrm{D}_{2} \mathrm{O}$ produced changes implying complex formation with fast exchange on the NMR chemical shift timescale. A series of spectra from the addition of cellobiose $\mathbf{1 5}$ to 7 are shown in Fig. 2. Signal movements were observed for receptor protons from all the aromatic units (pyrene, biphenyl and isophthaloyl spacer). The signal due to internally directed spacer protons s4' showed especially large movements and could be followed throughout the titration. Analysis of the chemical shift changes $(\Delta \delta)$ according to a $1: 1$ binding model yielded a binding constant of $260 \mathrm{M}^{-1}$. Similar analyses were performed for mannose, galactose, methyl $\beta$-glucoside and methyl $\beta$ - $N$-acetylglucosaminide (GlcNAc- $\beta$-OMe). 

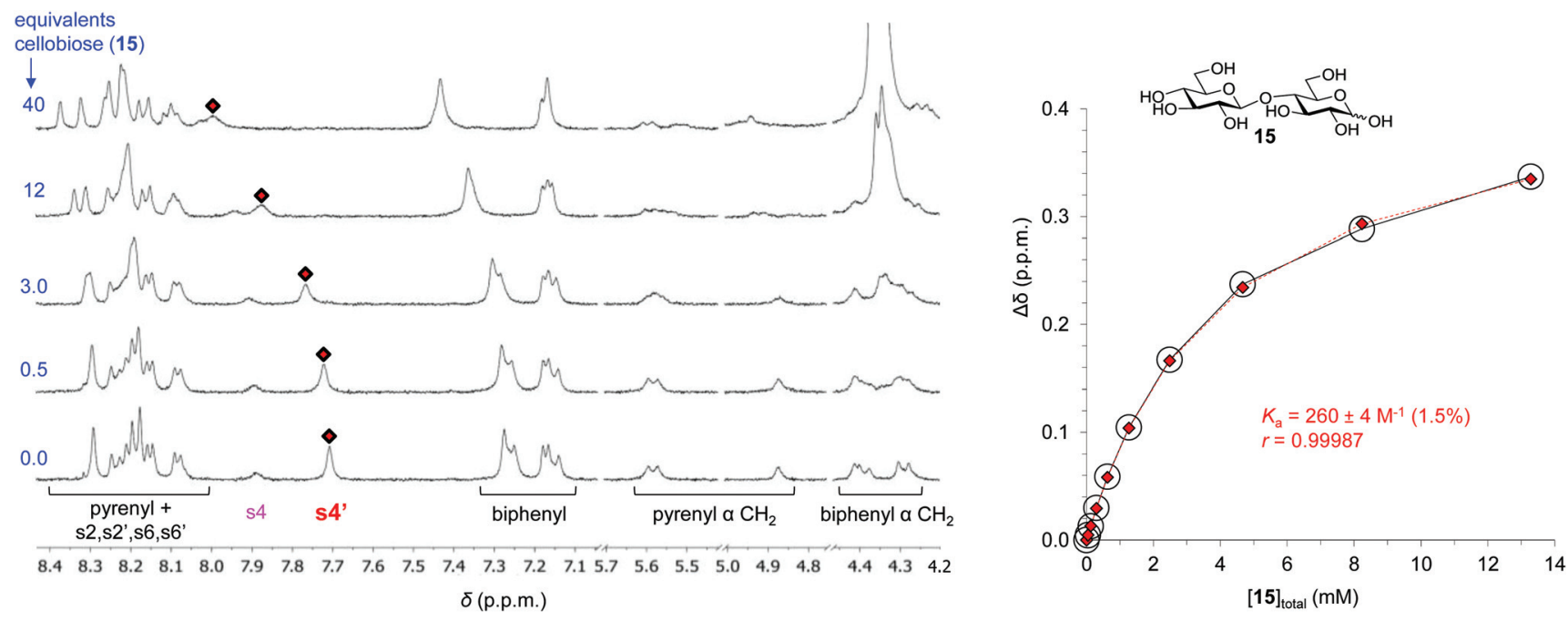

Fig. 2 Left: partial ${ }^{1} \mathrm{H}$ NMR spectra from the addition of $\mathrm{D}$-cellobiose 15 to receptor 7 in $\mathrm{D}_{2} \mathrm{O}$. For proton labelling see Fig. $1 \mathrm{c}$. Right: binding analysis curve for the signal due to $s 4^{\prime}$. The red diamonds $(\diamond)$ and white circles $(O)$ represent the observed and calculated data based on a $1: 1$ binding model.

Table 1 Association constants measured for 7 and some published receptors to carbohydrates in $\mathrm{D}_{2} \mathrm{O}$

\begin{tabular}{lrrrr}
\hline & \multicolumn{4}{c}{$K_{\mathrm{a}}{ }^{a}\left[\mathrm{M}^{-1}\right]$} \\
\cline { 2 - 5 } Carbohydrate & $\mathbf{3}^{6 e}$ & $\mathbf{1 6}^{6 h}$ & $\mathbf{7}$ & $\mathbf{4}^{6 j}$ \\
\hline D-Mannose & $\sim 0$ & $\sim 0$ & 4 & 5 \\
D-Galactose & 2 & $\sim 0$ & 4 & 18 \\
Methyl $\beta$-D-glucoside (1, R = Me) & 28 & 5 & 20 & 240 \\
Methyl $\beta$-D- $N$-acetylglucosaminide (2, R = Me) & 630 & 19 & 38 & 270 \\
D-Cellobiose 15 & 17 & 52 & 260 & 3900
\end{tabular}

${ }^{a}$ Measured by NMR titration at 298 K. Estimated errors typically $<2-5 \%$ for values obtained in the present work.

The results are summarised in Table 1, where they are compared to those obtained from tricyclic biphenyl-based 3, bicyclic pyrene-based 4 and bicyclic biphenyl-based $16 .{ }^{6 h}$ As might be expected, the affinities of 7 for all-equatorial substrates such as 15 are intermediate between bis-biphenyl 16 and bispyrenyl 4. The asymmetry of 7 has had no clear effect on the selectivity, as substrates with axial $\mathrm{OH}$ groups (mannose and galactose) are still bound only weakly. However, this is not unexpected as the variable region of 7 was not specifically designed to accommodate a hydroxyl group.
Finally, as mentioned earlier, the synthesis of 7 was complicated by a side-product which appeared in the macrocyclisation step leading to $O$-protected precursor 6 . Separation from 6 was challenging but could be achieved using an HPLC stationary phase bearing $\mathrm{C}_{18}$ chains terminated with pentafluorophenyl groups. ${ }^{7}$ The side-product was obtained in a similar yield to $6(\sim 6 \%)$. NMR spectra were consistent with a bicyclic cage structure closely related to 6 but lacking a proton at C1 of the pyrene nucleus. Mass spectroscopy revealed a molecular weight greater than 6 by 32 mass units, and we concluded that the most likely structure was hydroperoxide $\mathbf{1 7}$. We presume that the hydroperoxide group was introduced via autoxidation, although there seem to be no previous examples for this process in pyrenes and very few in other condensed aromatics. ${ }^{9}$ However there is precedent to suggest that molecular oxygen might show enhanced reactivity within certain macrocyclic cavities, ${ }^{10}$ and this may represent a further example. $O$-Deprotection of $\mathbf{1 7}$ as for $\mathbf{6}$ gave a water-soluble cage which behaved similarly to 7, giving well-resolved NMR spectra in $\mathrm{D}_{2} \mathrm{O}$ and serving as a carbohydrate receptor. ${ }^{11}$ Indeed affinities for some carbohydrates were slightly higher than for $7^{7}$ For example the $K_{\mathrm{a}}$ to cellobiose $\mathbf{1 5}$ was measured at $335 \mathrm{M}^{-1}$, perhaps reflecting the advantage of an electron-donating oxygen substituent. ${ }^{12}$

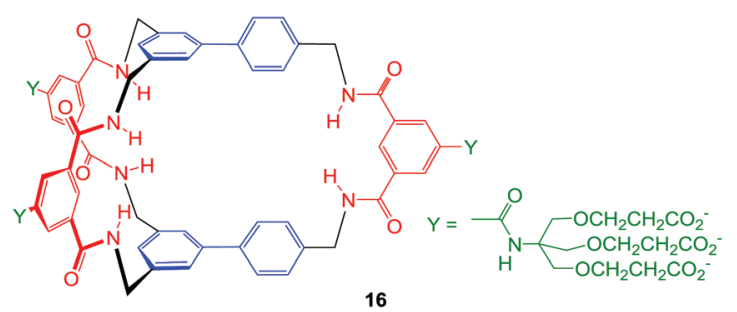

16

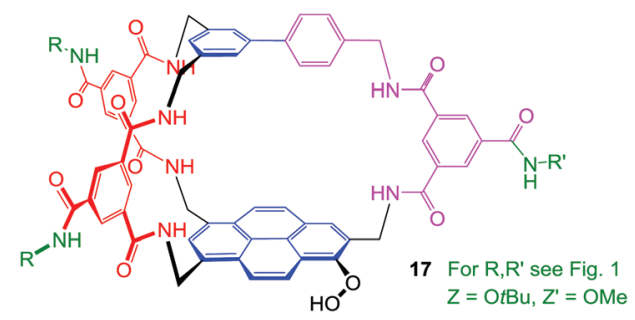


In conclusion we have demonstrated a synthetic strategy for desymmetrised carbohydrate receptors with potential for greater scope than presently available synthetic lectins. The yield of prototype 7 was limited by autoxidation, but this problem is unlikely to be general and should be controllable where necessary. The structure of 7 should be variable through incorporation of different roof units, perhaps in library format. This should allow tuning of the binding site to accept a greater range of carbohydrates. A further option is the construction of functionalised binding sites capable of stabilising transition states (e.g. for glycoside hydrolysis), leading to enzyme-like catalysis. Future work will be aimed at realising these possibilities.

\section{Acknowledgements}

This research was supported by the Engineering and Physical Sciences Research Council through grant number EP/I028501/1.

\section{Notes and references}

1 (a) D. Solis, N. V. Bovin, A. P. Davis, J. Jiménez-Barbero, A. Romero, R. Roy, K. Smetana and H. J. Gabius, Biochim. Biophys. Acta, Gen. Subj., 2015, 1850, 186-235; (b) H. J. Gabius, The Sugar Code: Fundamentals of Glycosciences, Wiley-VCH, Weinheim, 2009; (c) C. A. Aarnoudse, J. J. G. Vallejo, E. Saeland and Y. van Kooyk, Curr. Opin. Immunol., 2006, 18, 105-111; (d) C. R. Bertozzi and L. L. Kiessling, Science, 2001, 291, 2357-2364; (e) B. Wang and G. J. Boons, Carbohydrate Recognition: Biological Problems, Methods, and Applications, John Wiley \& Sons Ltd., New Jersey, 2011.

2 A. P. Davis, Org. Biomol. Chem., 2009, 7, 3629-3638.

3 E. J. Toone, Curr. Opin. Struct. Biol., 1994, 4, 719-728.

4 For reviews on synthetic carbohydrate receptors see: (a) A. P. Davis and R. S. Wareham, Angew. Chem., Int. Ed., 1999, 38, 2978-2996; (b) S. Jin, Y. F. Cheng, S. Reid, M. Y. Li and B. H. Wang, Med. Res. Rev., 2010, 30, 171-257; (c) M. Mazik, Chem. Soc. Rev., 2009, 38, 935-956; (d) Y. Nakagawa and Y. Ito, Trends Glycosci. Glycotechnol., 2012, 24, 1-12; (e) C. E. Miron and A. Petitjean, ChemBioChem, 2015, 16, 365-379. Recent examples: $(f)$ N. Chandramouli, Y. Ferrand, G. Lautrette, B. Kauffmann, C. D. Mackereth, M. Laguerre, D. Dubreuil and I. Huc, Nat. Chem., 2015, 7, 334-341; (g) Y. Jang, R. Natarajan, Y. H. Ko and K. Kim, Angew. Chem., Int. Ed., 2014, 53, 1003-1007; (h) J. Lippe and M. Mazik, J. Org. Chem., 2015, 80, 1427-1439; (i) O. Francesconi, M. Gentili, C. Nativi, A. Arda, F. J. Canada, J. Jiménez-Barbero and S. Roelens, Chem. - Eur. J., 2014, 20, 6081-6091; (j) M. Rauschenberg, S. Bandaru, M. P. Waller and B. J. Ravoo, Chem. - Eur. J., 2014, 20, 2770-2782; (k) A. Schmitt, O. Perraud, E. Payet, B. Chatelet, B. Bousquet, M. Valls, D. Padula, L. Di Bari, J. P. Dutasta and A. Martinez, Org. Biomol. Chem., 2014, 12, 4211-4217; (l) S. M. Bromfield, P. Posocco, C. W. Chan, M. Calderon, S. E. Guimond, J. E. Turnbull, S. Pricl and D. K. Smith, Chem. Sci., 2014, 5, 1484-1492; ( $m$ ) S. Rieth, M. R. Miner, C. M. Chang, B. Hurlocker and A. B. Braunschweig, Chem. Sci., 2013, 4, 357-367.

5 J. Balzarini, Nat. Rev. Microbiol., 2007, 5, 583-597.

6 (a) E. Klein, M. P. Crump and A. P. Davis, Angew. Chem., Int. Ed., 2005, 44, 298-302; (b) Y. Ferrand, M. P. Crump and A. P. Davis, Science, 2007, 318, 619-622; (c) E. Klein, Y. Ferrand, E. K. Auty and A. P. Davis, Chem. Commun., 2007, 2390-2392; (d) N. P. Barwell, M. P. Crump and A. P. Davis, Angew. Chem., Int. Ed., 2009, 48, 7673-7676; (e) Y. Ferrand, E. Klein, N. P. Barwell, M. P. Crump, J. Jiménez-Barbero, C. Vicent, G.-J. Boons, S. Ingale and A. P. Davis, Angew. Chem., Int. Ed., 2009, 48, 1775-1779; (f) C. Ke, H. Destecroix, M. P. Crump and A. P. Davis, Nat. Chem., 2012, 4, 718-723; (g) B. Sookcharoenpinyo, E. Klein, Y. Ferrand, D. B. Walker, P. R. Brotherhood, C. Ke, M. P. Crump and A. P. Davis, Angew. Chem., Int. Ed., 2012, 51, 4586-4590; (h) J. D. Howgego, C. P. Butts, M. P. Crump and A. P. Davis, Chem. Commun., 2013, 49, 3110-3112; (i) H. Destecroix, C. M. Renney, T. J. Mooibroek, T. S. Carter, P. F. N. Stewart, M. P. Crump and A. P. Davis, Angew. Chem., Int. Ed., 2015, 54, 2057-2061; (j) T. J. Mooibroek, J. M. Casas-Solvas, R. L. Harniman, C. M. Renney, T. S. Carter, M. P. Crump and A. P. Davis, Nat. Chem., 2016, 8, 69-74.

7 For details see ESI. $\dagger$

8 J. R. White, G. J. Price, S. Schiffers, P. R. Raithby, P. K. Plucinski and C. G. Frost, Tetrahedron Lett., 2010, 51, 3913-3917.

9 Only two examples were found in Reaxys, both relating to electron-rich tricyclic aromatic systems. See: J. Rigaudy and G. Izoret, C. R. Acad. Sci., 1954, 238, 824-826; R. Knoesel, B. Gebus and J. Parrod, Bull. Soc. Chim. Fr., 1971, 4471.

10 J. J. Gassensmith, J. M. Baumes, J. Eberhard and B. D. Smith, Chem. Commun., 2009, 2517-2519.

11 The identity of this water-soluble receptor is uncertain, as the hydroperoxide unit may not have survived the deprotection step. Unfortunately we were unable to obtain MS data for the deprotected cage, a common problem with our polycarboxylic-substituted receptors. For further discussion see ESI. $\dagger$

12 N. P. Barwell and A. P. Davis, J. Org. Chem., 2011, 76, 65486557; K. L. Hudson, G. J. Bartlett, R. C. Diehl, J. Agirre, T. Gallagher, L. L. Kiessling and D. N. Woolfson, J. Am. Chem. Soc., 2015, 137, 15152-15160. 